\title{
Early Life Body Size in Relation to First Intracerebral or Subarachnoid Hemorrhage
}

\author{
Line K. Gjærde, ${ }^{\mathrm{a}, \mathrm{b}}$ Thomas C. Truelsen, ${ }^{\mathrm{c}}$ Thorkild I. A. Sørensen, ${ }^{\mathrm{a}, \mathrm{d}}$ Jennifer L. Baker ${ }^{\mathrm{a}, \mathrm{b}}$ \\ ${ }^{a}$ Novo Nordisk Foundation Center for Basic Metabolic Research, Section of Metabolic Genetics, Faculty of Health and Medical Sciences, \\ University of Copenhagen, Copenhagen, Denmark \\ ${ }^{b}$ Center for Clinical Research and Prevention, Bispebjerg and Frederiksberg Hospital, The Capital Region, Copenhagen, Denmark \\ 'Department of Neurology, Rigshospitalet, The Capital Region, Copenhagen, Denmark \\ ${ }^{\mathrm{d}}$ Department of Public Health, Section of Epidemiology, Faculty of Health and Medical Sciences, University of Copenhagen, Copenhagen, Denmark
}

Background and Purpose As risk of hemorrhagic stroke may have early life origins, we investigated associations of birth weight and childhood body mass index (BMI) with adult intracerebral hemorrhage (ICH) or subarachnoid hemorrhage (SAH).

Methods We included 240,234 Danish schoolchildren, born 1936 to 1989, with information on birth weight and measured weights and heights from 7 to 13 years. We calculated hazard ratios (HRs) and confidence intervals (Cls) for the associations between early life anthropometrics and $\mathrm{ICH}$ or SAH, identified through linkage with national registers.

Results During the study period, 1,947 individuals (39\% women) experienced an ICH and 797 individuals (64\% women) experienced a SAH. Per $500 \mathrm{~g}$ increase in birth weight, women had a $10 \%$ decreased risk of SAH ( $\mathrm{HR}, 0.90 ; 95 \% \mathrm{Cl}, 0.83$ to 0.97$)$ and men had a $10 \%$ decreased risk of $\mathrm{ICH}(\mathrm{HR}, 0.90 ; 95 \% \mathrm{Cl}, 0.85$ to 0.95). Birth weight was not associated with risks of ICH in women or SAH in men. In men, a childhood BMI below average (BMI z-score $<0$ ) was associated with increased risks of $\mathrm{ICH}$. The association was stronger at older childhood ages, and at 13 years a BMI z-score of -1 was associated with a HR of 1.17 (95\% Cl, 1.06 to 1.28), and a BMI z-score of -2 with a HR of $1.46(95 \% \mathrm{Cl}, 1.17$ to 1.82$)$ for $\mathrm{ICH}$. Childhood BMI was not associated with risks of $\mathrm{ICH}$ in women or with risks of SAH in both sexes.

Conclusions Early life body size is associated with ICH and SAH, and the associations differ by sex.
Correspondence: Line Klingen Gjærde Center for Clinical Research and Prevention, Bispebjerg and Frederiksberg Hospital, Nordre Fasanvej 57, Entrance 5, 1st floor, 2000 Frederiksberg, Denmark Tel: +45-38163072

E-mail: line.klingen.gjaerde@regionh.dk

Received: July 17, 2018

Revised: September 11, 2018 Accepted: September 24, 2018

Keywords Birth weight; Body mass index; Child; Cohort studies; Hemorrhage; Stroke

\section{Introduction}

While the incidence of hemorrhagic stroke has decreased worldwide, an increase in incidence has been observed in lowand middle-income countries, ${ }^{1}$ and intracerebral hemorrhages (ICHs) and subarachnoid hemorrhages (SAHs) are still the dominating causes of stroke-related deaths worldwide. ${ }^{2}$ More men than women are diagnosed with an $\mathrm{ICH}$, whereas the opposite is the case for SAH. Moreover, in contrast to ischemic stroke, ICH and SAH often occur at younger adult ages. ${ }^{1}$ The subdivision of hemorrhagic stroke is primarily based on the location of the bleeding, but the etiology of $\mathrm{ICH}$ and SAH also differs. An ICH is typically a result of small vessel disease due to chronic hypertension, which causes micro-aneurysms that subsequently rupture, ${ }^{3,4}$ whereas ruptured larger aneurysms usually cause $\mathrm{SAH}^{3}{ }^{3}$ It is therefore likely that these two hemorrhagic stroke subtypes also have different relationships with early life risk factors and that these relations may differ by sex. 
Low birth weight has been identified as a risk factor for ischemic stroke, but most studies do not distinguish between the major stroke subtypes so the results may be different for $\mathrm{ICH}$ and SAH because of the difference in aetiology. ${ }^{5}$ Studies investigating the influence of childhood body mass index (BMI) on stroke are limited by low numbers of stroke cases thus restricting their possibilities of conducting sex-specific analyses and investigating stroke subtypes. ${ }^{6-10}$ This may be why childhood $\mathrm{BMI}$ is not yet included as a risk factor in itself in the stroke prevention guidelines like birth weight is. We recently found that having a BMI above average at 7 to 13 years or having an above average gain in BMI in that period of childhood increases the risk of experiencing an ischemic stroke in early adulthood (before age 55 years) in women and men. ${ }^{11}$ Another recent study reported positive associations of gain in BMI from 8 to 20 years, but not with childhood BMI in itself, with risks of ischemic stroke as well as with ICH among Swedish men. ${ }^{10}$ However, apart from only including men, this study did not investigate effects of birth weight nor did it include SAH as an outcome.

We investigated associations of birth weight, childhood BMI and change in BMI from 7 to 13 years with later risk of ICH or SAH separately for women and men, in a cohort of Danish schoolchildren born from 1936 to 1989.

\section{Methods}

We used the computerized Copenhagen School Health Records Register (CSHRR) ${ }^{12}$ with information on birth weight and annually measured weights and heights of 372,636 children, who were born between 1930 and 1989. The register contains virtually every child who attended a public or private school in the Copenhagen Municipality. The children were examined during their school years (7 to 13 years) by trained school physicians and nurses using standard procedures. Birth weight, as reported by the parents at the first school health visit, was available for children born in 1936 and onwards.

Since 1968, all Danish citizens have been assigned a unique identification number, and by using this number we were able to link the information contained in the CSHRR with the Danish National Patient Registry, which contains all hospital discharge diagnosis since 1977, ${ }^{13}$ and with the computerized Danish Cause of Death Register, which was established in 1970. ${ }^{14}$

We identified stroke events by using the International Classification of Disease (ICD) System. In Denmark the 8th revision was used until 1994, and the 10th revision was used thereafter. All first-ever diagnoses of non-traumatic ICH (ICD-8: 431; ICD10: I61) and non-traumatic SAH (ICD-8: 430; ICD-10: I60) were retrieved for the individuals included in the CSHRR.
We followed the children from 1977, when the Danish National Patient Registry was established, or from age 25 years, until the first ICH or SAH event, loss to follow-up, emigration, death by another cause or 31st December 2015. The analyses were conducted on anonymous data, and the study was approved by the Danish Data Protection Agency. According to Danish law, ethical approval or informed consent is not required for purely register-based research.

\section{Statistical analysis}

Children with extreme values of birth weight $(<2.0$ or $>5.5 \mathrm{~kg}$ ) were excluded from the analyses to avoid including children with low birth weight due to prematurity, as well as children of diabetic mothers, which may be overrepresented in very high birth weight group. BMI was calculated $\left(\mathrm{kg} / \mathrm{m}^{2}\right)$ and transformed into z-scores based on an internal reference of children born between 1955 and 1959, where the prevalence of obesity was low and stable in Denmark.

We used Cox proportional hazards regression, with age as the underlying time axis, to investigate associations of birth weight and childhood $\mathrm{BMI}$ with $\mathrm{ICH}$ or $\mathrm{SAH}$ separately among women and men. We investigated the shape of the associations by using a categorical model and a restricted cubic spline model with 3 knots. Linearity was investigated by testing the linear model against these two models, using the likelihood ratio test. We tested the proportional hazards assumption by comparing the associations within quartiles of age. Potential interactions between birth weight and BMI in the association with $\mathrm{ICH}$ or $\mathrm{SAH}$ were investigated using the likelihood ratio test. When investigating change in BMI from 7 to 13 years we divided BMI into four groups at age 7 and 13 years based on the International Obesity Task Force (IOTF) cut-offs from $2012^{15}$ for thinness, normal weight, overweight and obesity (corresponding to BMI $<18.5,18.5$ to $25,>25$ to 30 , and $>30 \mathrm{~kg} / \mathrm{m}^{2}$ at age 18 years) and compared children who decreased or increased in BMI category between 7 and 13 years with the reference group of children who stayed in the normal weight category. Because major societal changes as well as changes in treatment and management of stroke and stroke risk factors occurred during the study period, all analysis were stratified by birth cohorts (5-year intervals) and we also formally investigated if the associations differed by birth cohort by the likelihood ratio test.

As imaging by computed tomography and magnetic resonance imaging was implemented during the years included in the study, we conducted a sensitivity analysis investigating the associations among those who were diagnosed during the last 10 years of follow-up, and who therefore were likely to have a diagnosis based on imaging. 


\section{Results}

The study population consisted of 240,234 women and men included in the CSHRR with information on birth weight and at least one measure of childhood BMI (Figure 1). During the years of follow-up (mean follow-up time, 28.2 years) 762 women and 1,185 men were diagnosed with an $\mathrm{ICH}$, and 507 women and 290 men were diagnosed with $\mathrm{SAH}$. The incidence rate of $\mathrm{ICH}$ increased with age, but more steeply in men, whereas the incidence rate for $\mathrm{SAH}$ seemed to be highest in the middle-aged years in both sexes (Figure 2). Small differences in birth weight and childhood BMI were observed between those who did not experience any hemorrhagic stroke later in life versus those who did (Table 1).

\section{Intracerebral hemorrhage}

We found indications of different associations of birth weight with risks of $\mathrm{ICH}$ in women compared with men (likelihood ratio test for sex-interactions, $P=0.02$ ). Lower birth weight was not associated with ICH among women but was in men for whom a $500 \mathrm{~g}$ increase in birth weight was associated with a $10 \%$ decrease in the risk of ICH (Figure 3 ).

For of the associations between childhood BMI and later ICH we found a similar pattern at all childhood ages, and therefore only present results for age 7 and 13 years (Figure 4, other ages are presented in Supplementary Figure 1). Among women, we did not find that childhood BMI was associated with later risks of $\mathrm{ICH}$. Among men, however, we found a non-linear pattern, where men who had a childhood BMI below average (BMI z-score below 0), had increased risks of $\mathrm{ICH}$. The risk of $\mathrm{ICH}$ was higher among those with lowest BMI z-scores and the associations were stronger at older ages in childhood. At age 13 years, having a BMI z-score of -2 was associated with a hazard ratio (HR) of 1.46 (95\% confidence interval [Cl], 1.17 to 1.82 ), and a BMI z-score of -1 was associated with a HR of 1.17 (95\% Cl, 1.06 to 1.28 ) for $\mathrm{ICH}$. We found no interactions with birth weight in the association between childhood BMI and ICH (likelihood ratio test, all $P>0.20$ ). Further, as illustrated in

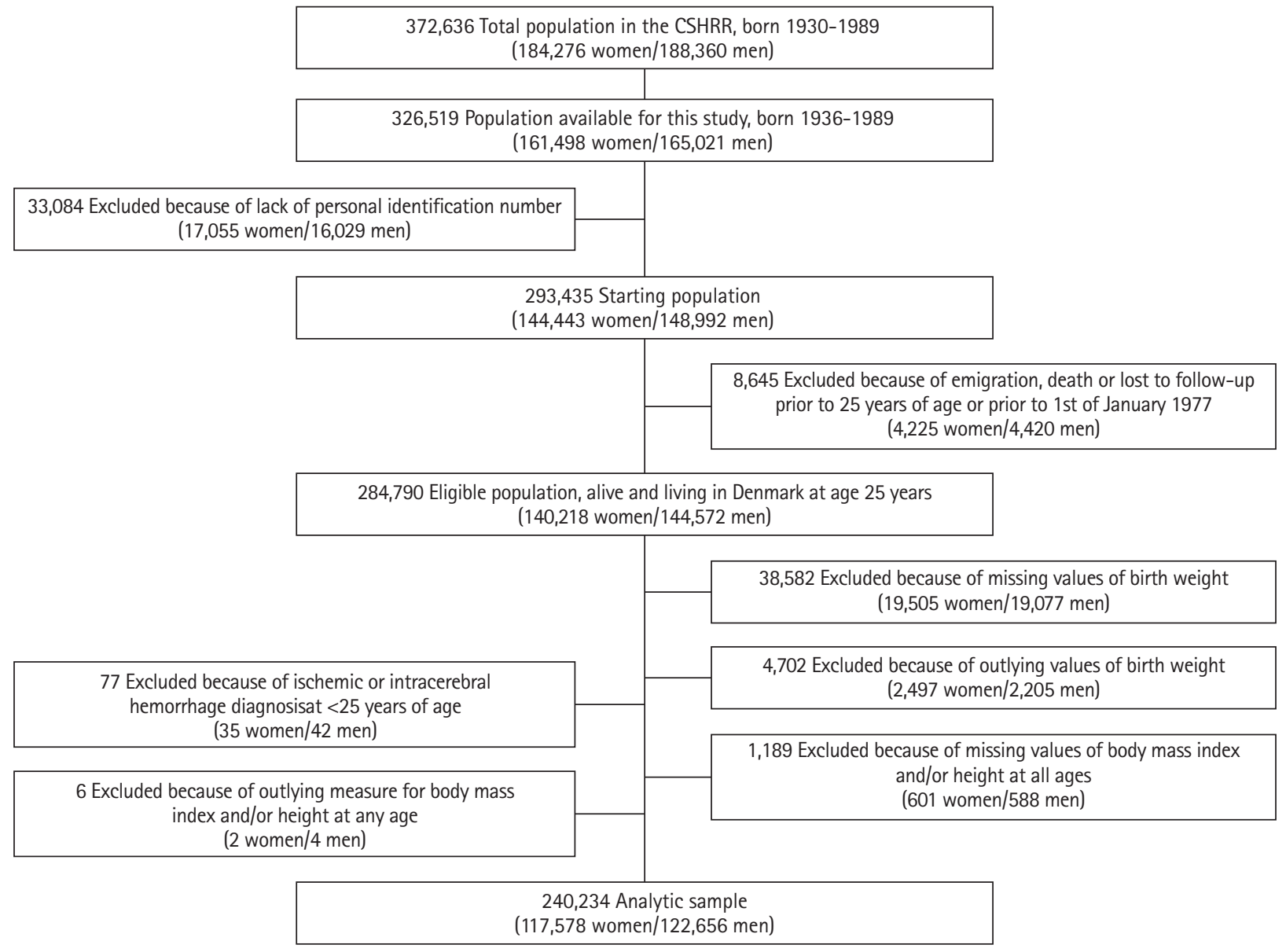

Figure 1. Flowchart describing the criteria of eligibility in the overall study $(n=240,234)$, based on data from the Copenhagen School Health Records Register (CSHRR). 
Figure 4, adjusting the childhood BMI-ICH results for birth weight only minimally affected the associations between childhood BMI and ICH.

Change in BMI from 7 to 13 years was not associated with risks of $\mathrm{ICH}$ among women, but was in men (Table 2). Men who were defined as normal-weight at age 7 but thin at age 13 years also had increased risks of $\mathrm{ICH}(\mathrm{HR}, 1.33 ; 95 \% \mathrm{Cl}, 1.05$ to 1.70), whereas men defined as thin according to the IOTF cutoffs at both ages 7 and 13 years only showed a tendency to an increased risk of $\mathrm{ICH}(\mathrm{HR}, 1.19 ; 95 \% \mathrm{Cl}, 0.90$ to 1.84).

None of the associations differed according to age at diagnosis (all P>0.05, except for BMI at 10 and 13 years among boys, with $P$-values of 0.04 , when investigating potential interactions between quartiles of age at diagnosis using the likelihood ratio test), or according to birth cohort (all $P>0.20$ when investigating potential interactions between birth cohorts us- ing the likelihood ratio test).

When restricting the analysis to only cases of $\mathrm{ICH}$ diagnosed within the last 10 years, we found similar results (Supplementary Table 1 and Supplementary Figure 2).

\section{Subarachnoid hemorrhage}

For SAH, we found that women who were small at birth had an increased risk; a $500 \mathrm{~g}$ increase in birth weight was associated with a $10 \%$ decreased risk of SAH. Among men birth weight was not associated with SAH (Figure 3). The sex-difference in the associations was however not statistically significant (likelihood ratio test for sex-interactions, $P=0.10$ ).

Childhood BMI at any age was not associated with $\mathrm{SAH}$ in women or in men, and therefore only results for age 7 and 13 years are presented (Table 3, other ages are presented in Supplementary Table 2). Moreover, we did not detect any interac-
Intracerebral hemorrhage

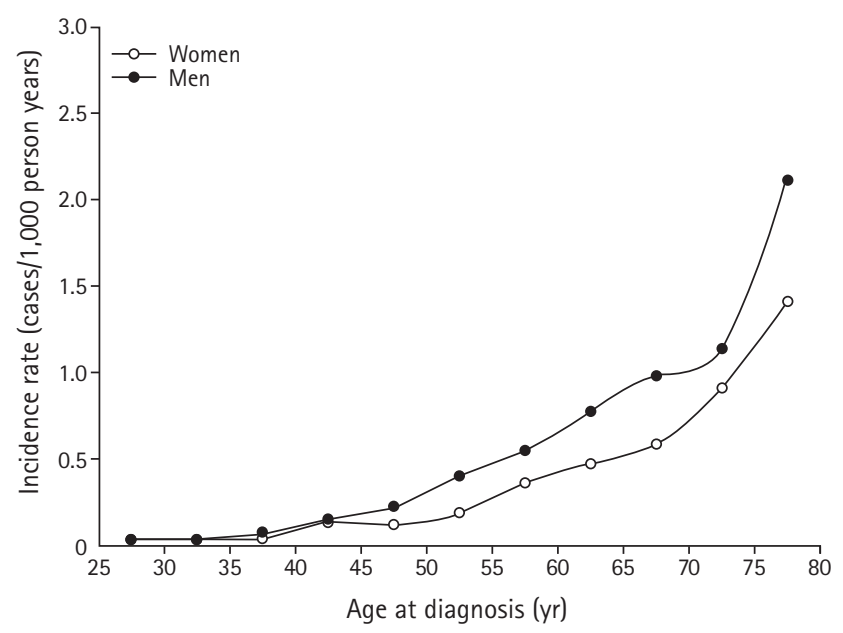

Subarachnoid hemorrhage

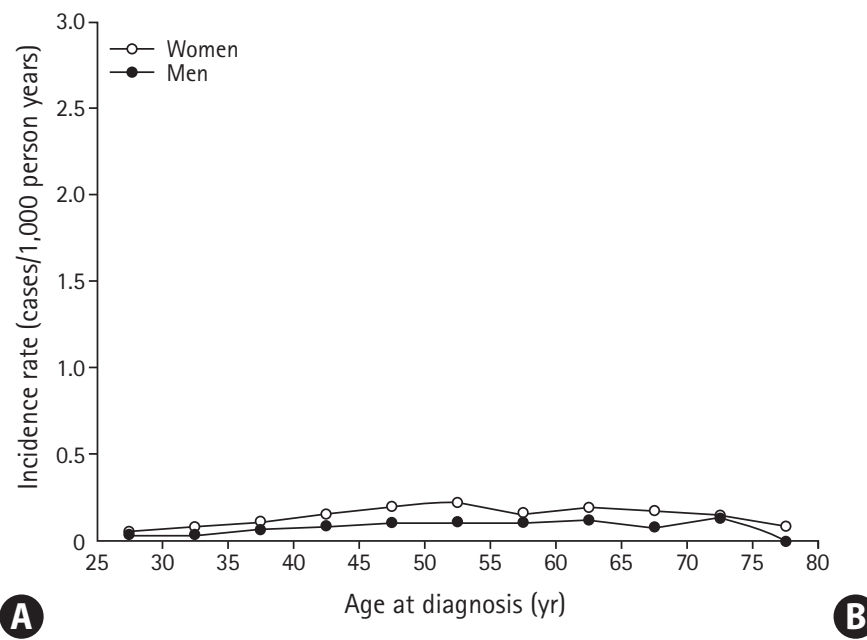

Figure 2. Incidence rate of adult hemorrhagic stroke (cases per 1,000 person-years) for each subtype according to age at diagnosis. (A) Intracerebral hemorrhage. (B) Subarachnoid hemorrhage.

Table 1. Birth weight and childhood BMI with SD among women and men

\begin{tabular}{|c|c|c|c|c|c|c|}
\hline \multirow{2}{*}{ Anthropometric value } & \multicolumn{2}{|c|}{ Non-cases } & \multicolumn{2}{|c|}{ Intracerebral hemorrhage cases } & \multicolumn{2}{|c|}{ Subarachnoid hemorrhage cases } \\
\hline & Number & Mean $\pm S D$ & Number & Mean $\pm S D$ & Number & Mean $\pm S D$ \\
\hline \multicolumn{7}{|l|}{ Women } \\
\hline Birth weight & 116,309 & $3.31 \pm 0.52$ & 762 & $3.32 \pm 0.55$ & 507 & $3.25 \pm 0.58$ \\
\hline BMl at age $7 \mathrm{yr}$ & 111,197 & $15.5 \pm 1.4$ & 715 & $15.3 \pm 1.3$ & 482 & $15.3 \pm 1.3$ \\
\hline $\mathrm{BMl}$ at age $13 \mathrm{yr}$ & 100,691 & $18.7 \pm 2.5$ & 717 & $18.6 \pm 2.4$ & 487 & $18.5 \pm 2.2$ \\
\hline \multicolumn{7}{|l|}{ Men } \\
\hline Birth weight & 121,181 & $3.43 \pm 0.55$ & 1,185 & $3.39 \pm 0.55$ & 290 & $3.45 \pm 0.54$ \\
\hline BMl at age $7 \mathrm{yr}$ & 115,820 & $15.6 \pm 1.3$ & 1,127 & $15.5 \pm 1.2$ & 277 & $15.4 \pm 1.1$ \\
\hline $\mathrm{BMI}$ at age $13 \mathrm{yr}$ & 103,629 & $18.2 \pm 2.3$ & 1,112 & $18.0 \pm 2.2$ & 276 & $18.0 \pm 2.0$ \\
\hline
\end{tabular}

$\mathrm{BMI}$, body mass index; SD, standard deviation. 
tions between birth weight and BMI in the association with SAH (likelihood ratio test, all $P>0.20$ ), and adjusting the childhood BMI-SAH associations for birth weight did not change

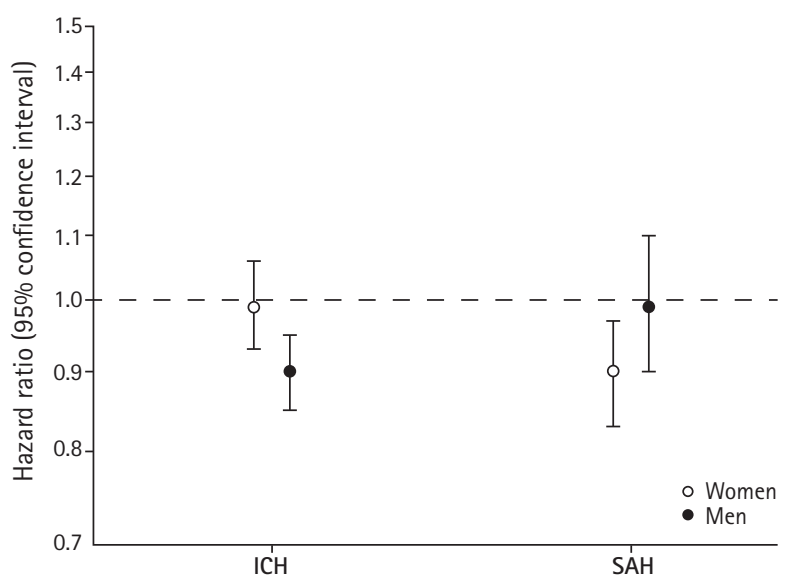

Figure 3. Risks of intracerebral hemorrhage (ICH) or subarachnoid hemorrhage (SAH) per $500 \mathrm{~g}$ increase in birth weight among women and men. the findings (Table 3).

For this hemorrhagic stroke subtype, the number of cases in the different BMI-strata was too low to provide reliable estimates of risks. We did not find that the associations differed according to age at diagnosis or according to birth cohort (all P>0.10 or P>0.20, respectively, when using the likelihood ratio test).

The sensitivity analysis based on cases SAH diagnosed within the last 10 years revealed similar results (Supplementary Tables 1 and 3).

\section{Discussion}

In this large population-based cohort of Danish schoolchildren, we found that lower birth weight was associated with increased risks of SAH in women and with increased risks of $\mathrm{ICH}$ in men. In women childhood BMI was not associated with risks of $\mathrm{ICH}$, whereas men who had a BMI below average during the school years had increased risks of ICH. No associations be-
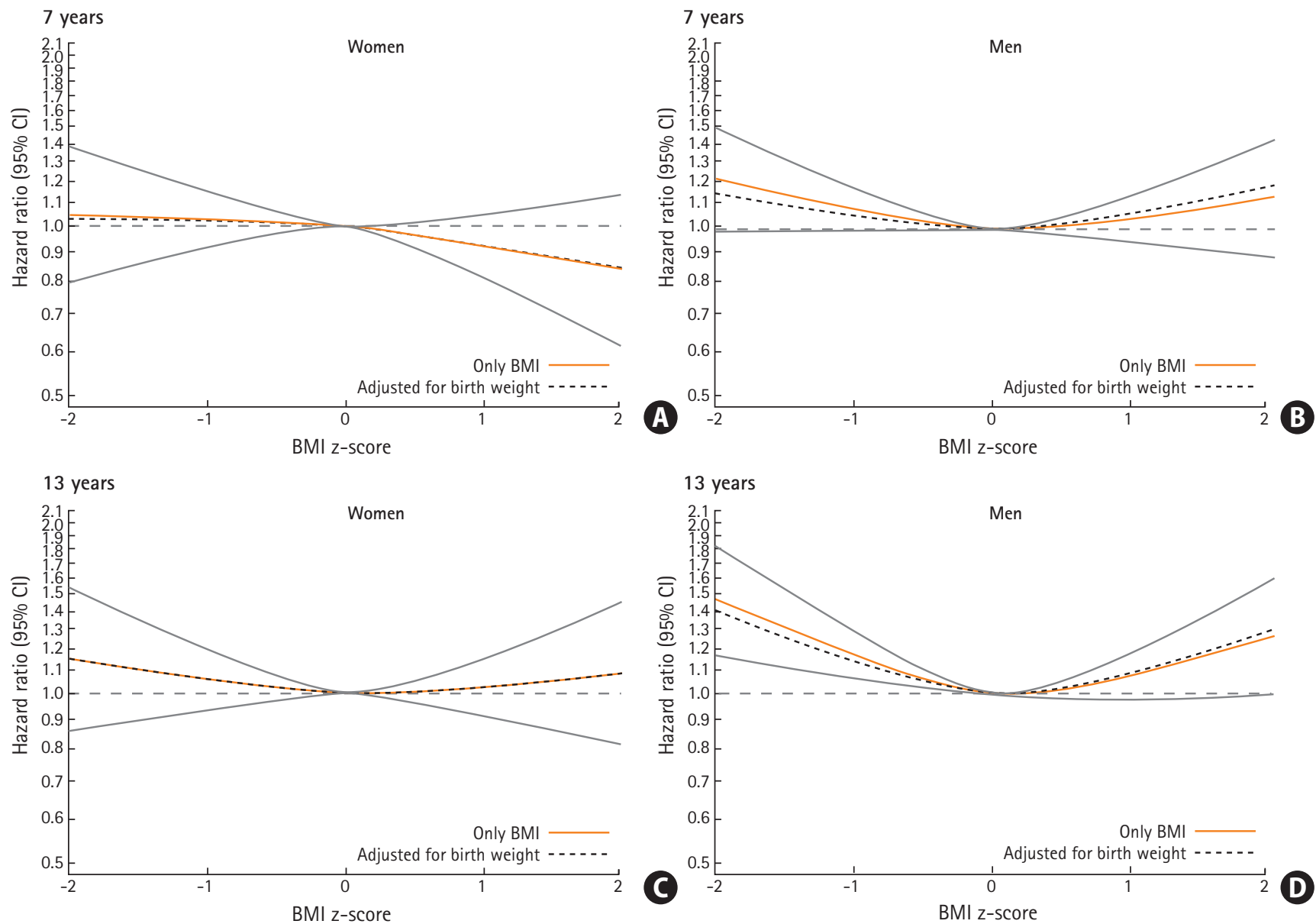

Figure 4. Hazard ratios (HRs) with confidence intervals (Cls) for the association between childhood body mass index (BMI) at age 7 and 13 years and risks of intracerebral hemorrhage among women and men. (A) Women, 7 years. (B) Men, 7 years. (C) Women, 13 years. (D) Men, 13 years. 
tween childhood BMI and SAH in either sex were found, and change in BMI during childhood was not related in itself with ICH in women, but in men those who became thin during childhood had increased risks of ICH.

In contrast to prior studies, we identified sex-differences in the associations between birth weight and risks of hemorrhagic stroke according to subtype. In the Helsinki Birth Cohort, birth weight was inversely associated with increased risks of $\mathrm{ICH}$ and SAH combined, but only when adjusting for head circumference. ${ }^{8,9}$ This and our findings are in accordance with what was found in the Nurses' Health Study, where a lack of an association between birth weight and hemorrhagic stroke among women was reported. ${ }^{16}$ However, in the Aberdeen Children of the 1950's study and in a cohort from Uppsala strong inverse associations of birth weight with $\mathrm{ICH}$ and $\mathrm{SAH}$ in women and men combined were observed. ${ }^{17,18}$ Nonetheless, in an updated analysis on the Uppsala cohort this association disappeared when women and men were examined separately even though almost 30\% of the cohort participants had a stroke. ${ }^{19}$

Surprisingly, we found that a childhood BMI below average was associated with increased risks of $\mathrm{ICH}$ among men, and we also found that changing from being classified as normal weight to thin from 7 to 13 years was associated with increased risks of $\mathrm{ICH}$ among men. These findings contrast with what a study on Swedish men that included 207 cases of ICH showed; where childhood BMI was not associated with $\mathrm{ICH}_{\text {, }}$ but gain in BMI from 8 to 20 years and adult BMI were positively associated with $\mathrm{ICH}^{10}{ }^{10}$ One of the studies based on the Helsinki Birth Cohort reported that the findings of an association between lower BMI at age 7 years, but not at age 11 years, and total stroke, were similar for ischemic and hemorrhagic stroke (i.e., ICH and SAH combined). ${ }^{9}$ Generally, in adults both low and very high $\mathrm{BMI}$ are suggested to have associations with hemorrhagic stroke, but the studies that have investigated this

Table 2. Change in childhood BMI according to IOTF category between 7 and 13 years and risks of ICH among women and men

\begin{tabular}{|c|c|c|c|c|c|c|}
\hline & Ser & IOTE definition & & & ears & \\
\hline & $\int x$ & 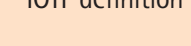 & Thinness & Normal weight & Overweight & Obesity \\
\hline $\begin{array}{l}\text { BMI at } 7 \\
\text { years }\end{array}$ & Women & Thinness & $\begin{array}{c}0.91(0.64-1.28) \\
\text { Cases }=35\end{array}$ & $\begin{array}{c}1.19(0.82-1.70) \\
\text { Cases=31 }\end{array}$ & $\begin{array}{c}- \\
\text { Cases }=0\end{array}$ & $\begin{array}{c}- \\
\text { Cases }=0\end{array}$ \\
\hline & & Normal weight & $\begin{array}{c}1.01(0.76-1.34) \\
\text { Cases }=54\end{array}$ & $\begin{array}{c}1(\mathrm{ref}) \\
\text { Cases=502 }\end{array}$ & $\begin{array}{c}1.02(0.67-1.53) \\
\text { Cases }=24\end{array}$ & $\begin{array}{c}- \\
\text { Cases }=0\end{array}$ \\
\hline & & Overweight & $\begin{array}{c}- \\
\text { Cases=0 }\end{array}$ & $\begin{array}{c}0.72(0.40-1.27) \\
\text { Cases }=12\end{array}$ & $\begin{array}{c}1.16(0.72-1.89) \\
\text { Cases }=17\end{array}$ & $\begin{array}{c}- \\
\text { Cases }=1\end{array}$ \\
\hline & & Obesity & $\begin{array}{c}- \\
\text { Cases }=0\end{array}$ & $\begin{array}{c}- \\
\text { Cases }=0\end{array}$ & $\begin{array}{c}- \\
\text { Cases }=1\end{array}$ & $\begin{array}{c}- \\
\text { Cases }=1\end{array}$ \\
\hline & Men & Thinness & $\begin{array}{c}1.19(0.90-1.84) \\
\text { Cases }=54\end{array}$ & $\begin{array}{c}0.89(0.62-1.28) \\
\text { Cases }=30\end{array}$ & $\begin{array}{c}- \\
\text { Cases }=0\end{array}$ & $\begin{array}{c}- \\
\text { Cases }=0\end{array}$ \\
\hline & & Normal weight & $\begin{array}{c}1.33(1.05-1.70) \\
\text { Cases=73 }\end{array}$ & $\begin{array}{c}1(\mathrm{ref}) \\
\text { Cases=825 }\end{array}$ & $\begin{array}{c}1.26(0.92-1.73) \\
\text { Cases }=41\end{array}$ & $\begin{array}{c}- \\
\text { Cases }=2\end{array}$ \\
\hline & & Overweight & $\begin{array}{c}- \\
\text { Cases }=0\end{array}$ & $\begin{array}{c}0.75(0.39-1.44) \\
\text { Cases }=9\end{array}$ & $\begin{array}{c}1.39(0.87-2.22) \\
\text { Cases }=18\end{array}$ & $\begin{array}{c}- \\
\text { Cases }=1\end{array}$ \\
\hline & & Obesity & $\begin{array}{c}- \\
\text { Cases }=0\end{array}$ & $\begin{array}{c}- \\
\text { Cases }=0\end{array}$ & $\begin{array}{c}4.62\left(\begin{array}{c}(1.92-11.15) \\
\text { Cases }=5\end{array}\right.\end{array}$ & $\begin{array}{c}- \\
\text { Cases }=0\end{array}$ \\
\hline
\end{tabular}

Values are presented as hazard ratio (95\% confidence interval) of ICH. Estimates in categories with less than five cases were excluded. All analyses are stratified by birth cohort.

BMI, body mass index; IOTF, International Obesity Task Force; ICH, intracerebral hemorrhage.

Table 3. Associations of childhood BMI at age 7 to 13 years with risks of SAH among women and men

\begin{tabular}{lccccc}
\hline \multirow{2}{*}{ Sex } & Age $(\mathrm{yr})$ & Number & Cases & \multicolumn{2}{c}{ SAH, HR (95\% Cl) } \\
\cline { 5 - 6 } & & & & Only BMI & Adjusted for birth weight \\
\hline \multirow{2}{*}{ Women } & 7 & 111,099 & 445 & $1.00(0.91-1.10)$ & $1.02(0.93-1.12)$ \\
& 13 & 101,107 & 449 & $0.95(0.86-1.04)$ & $0.96(0.87-1.06)$ \\
& 7 & 115,888 & 247 & $0.95(0.84-1.08)$ & $0.94(0.83-1.08)$ \\
& 13 & 104,225 & 248 & $0.94(0.83-1.08)$ & $0.94(0.82-1.08)$ \\
\hline
\end{tabular}

HRs and $95 \% \mathrm{Cls}$ are given for a 1-unit increase in BMI z-score. All analyses are stratified by birth cohort.

$\mathrm{BMI}$, body mass index; $\mathrm{SAH}$, subarachnoid hemorrhage; $\mathrm{HR}$, hazard ratio; $\mathrm{Cl}$, confidence interval. 
have mainly been focused on effects of high BMI. ${ }^{5}$

Studies in the United Kingdom identified low birth weight and normal head circumference as a risk factor for stroke mortality. ${ }^{20}$ They suggested that this was due to late disrupted gestational growth, as head growth occurs relatively early in gestation. The replication of these findings in the Helsinki Birth Cohort, however, led to the hypothesis that stroke originates through patterns of reduced fetal growth in which the brain is spared, and this phenomenon was termed brain-sparing. ${ }^{8}$ The authors further speculated that the redistribution of cardiac output in favor of the brain may cause permanent adverse changes of the structure of the major arteries in the truncus and brain. This may as well as compromise the development of the abdominal organs, including the kidneys, which later in life could lead to hypertension, the most important risk factor for hemorrhagic stroke.

Low birth weight has previously been linked with increased risks of later hypertension in a meta-regression study ${ }^{21}$ using results from 20 Nordic studies, including our cohort, which could also add to the explanation of why ICH is a male-dominant disease since men have a higher prevalence of hypertension than women in several adult populations, ${ }_{1}^{22,23}$ and men may in general carry a higher atherosclerotic load. However, the findings for childhood BMI in the current study are not in agreement with findings in our previous studies on associations of childhood BMI with hypertension ${ }^{24}$ and atherosclerotic diseases, such as ischemic stroke ${ }^{11}$ and coronary heart disease, ${ }_{1}^{25}$ where childhood BMI was positively associated with these outcomes in adulthood. Our findings of an association between childhood BMI below average and ICH among men is in accord with a study in adults ${ }^{26}$ that found similar associations between low BMI and increased risks of ICH. It is speculated that low cholesterol or other manifestations of cerebral small vessel disease may underlie this association as these are known risk factors of $\mathrm{ICH} .{ }^{5}$ However, this is speculative and does not explain why it only applies to men.

A potential reason for the sex-difference in the association between birth weight and SAH is smoking, being major risk factor of $\mathrm{SAH}_{1}{ }^{5}$ especially in women, ${ }_{1}^{27}$ and associated with low birth weight. If girls of smoking mothers are more likely to smoke as adults, this could potentially explain why we find an association between lower birth weight and SAH in women in our study.

In general, a plausible mechanism of our findings, although debatable due to the sex differences in the associations, is that poor intrauterine growth may cause permanent structural changes leading to malformations and local weakening of the arterial walls, which increases the likelihood of developing an- eurysms. In this context it is interesting to note that the main components of body size, bone, and cartilage are derived from the neural crest, which is also a developmental source of cerebral vasculature. Subsequently, the stress of being very thin and short in childhood, potentially due to a chronic illness and malnutrition, could have negative effects on these possible inborn arterial weaknesses or aneurysms and thus increase the risk of later rupture. However, although these explanations may have played a role, we find them less plausible in the population included in our study, where such health problems are very rare and where children were still well enough to attend school and annual health examinations. Furthermore, the differences in risks between men and women are not in agreement with this general explanation. One of our recent studies, showed that childhood height is inversely associated with $\mathrm{ICH}$ in men, but not in women, ${ }^{28}$ and we found inverse associations of childhood height with SAH in women, but not in men (Supplementary Table 4). Other sex-specific factors and pleiotropic genetic effects on growth and stroke risk deserve further investigations as possible underlying reasons for the associations observed in our study. Moreover, our findings may contribute to the explanation for the higher rates of hemorrhagic stroke in low- and middle-income countries, where stunting in childhood is still a problem.

This is a very large study with prospectively collected data on an unselected population of children from the Copenhagen area. The size and the age structure of the cohort made it possible to examine early life anthropometrics with later risks of rare types of stroke. We used measured as opposed to self-reported BMI, and although birth weight was not measured it was based on reasonably valid recall information ${ }^{29}$ from the parents already 7 years after birth. Moreover, the repeated measurements of weight and height allowed us to investigate change in BMI during childhood in relation to ICH. However, due to the low number of cases this analysis could not be performed for SAH. As childhood socioeconomic status is associated with increased risks of stroke and potentially more strongly with hemorrhagic stroke, ${ }_{1}^{30}$ it is possible that socioeconomic status could have influenced our results, but this information was not available in our study. We did, however, not find any differences in the results between birth cohorts despite major changes in living circumstances and distribution of risk factors, such as educational level, income, and marital status that happened during the study period of about five decades. Furthermore, our results remained the same when restricting the sample to those who were diagnosed within the last 10 years, thus eliminating the possibility of questionable diagnoses due to the lack of imaging. The mechanisms under- 
lying the inverse association between birth weight and SAH in women and $\mathrm{ICH}$ in men as well as the non-linear association between BMI and ICH among men are unclear, but hypertension, smoking and low cholesterol may be important. It was, however, out of the scope of this study to examine the role of these potential mediating or confounding factors.

\section{Conclusions}

Lower birth weight is associated with $\mathrm{SAH}$ in women and with $\mathrm{ICH}$ in men. Having a BMI below average in childhood or decreasing BMI to low levels during childhood increases the risks of ICH only among men, independently of birth weight. While these findings need to be replicated in populations with different risk factor distributions, they suggest there are sex-specific components in the etiologies of hemorrhagic stroke subtypes.

\section{Supplementary materials}

Supplementary materials related to this article can be found online at https://doi.org/10.5853/2018.02033.

\section{Disclosure}

Dr. Line Klingen Gjærde had support from the University of Copenhagen. Dr. Jennifer Lyn Baker was supported by the European Research Council under the European Union's Seventh Framework Programme (FP/2007-2013)/ERC (No.281419, childgrowth2cancer to Dr. Jennifer Lyn Baker) and the European Union's Horizon 2020 research and innovation programme No.633595, DynaHEALTH. The funders played no role in the preparation of the manuscript or the decision to submit for publication.

\section{Acknowledgments}

The Copenhagen School Health Records Register (CSHRR) was established by the former Institute of Preventive Medicine (now the Center for Clinical Research and Prevention). It was built in collaboration with the Copenhagen City Archives in Denmark.

\section{References}

1. Krishnamurthi RV, Feigin $\mathrm{VL}$, Forouzanfar $M H$, Mensah $G A$, Connor M, Bennett DA, et al. Global and regional burden of first-ever ischaemic and haemorrhagic stroke during 19902010: findings from the Global Burden of Disease Study 2010. Lancet Glob Health 2013;1:e259-e281.
2. Feigin $V L$, Roth $G A$, Naghavi $M$, Parmar $P$, Krishnamurthi $R$, Chugh $\mathrm{S}$, et al. Global burden of stroke and risk factors in 188 countries, during 1990-2013: a systematic analysis for the Global Burden of Disease Study 2013. Lancet Neurol 2016;15: 913-924.

3. Donnan GA, Fisher M, Macleod M, Davis SM. Stroke. Lancet 2008;371:1612-1623.

4. Qureshi Al, Mendelow AD, Hanley DF. Intracerebral haemorrhage. Lancet 2009;373:1632-1644.

5. Meschia JF, Bushnell C, Boden-Albala B, Braun LT, Bravata DM, Chaturvedi $S$, et al. Guidelines for the primary prevention of stroke: a statement for healthcare professionals from the American Heart Association/American Stroke Association. Stroke 2014;45:3754-3832.

6. Lawlor DA, Martin RM, Gunnell D, Galobardes B, Ebrahim S, Sandhu J, et al. Association of body mass index measured in childhood, adolescence, and young adulthood with risk of ischemic heart disease and stroke: findings from 3 historical cohort studies. Am J Clin Nutr 2006;83:767-773.

7. Lawlor DA, Leon DA. Association of body mass index and obesity measured in early childhood with risk of coronary heart disease and stroke in middle age: findings from the aberdeen children of the 1950s prospective cohort study. Circulation 2005;111:1891-1896.

8. Eriksson JG, Forsén T, Tuomilehto J, Osmond C, Barker DJ. Early growth, adult income, and risk of stroke. Stroke 2000;31:869874.

9. Osmond C, Kajantie E, Forsén TJ, Eriksson JG, Barker DJ. Infant growth and stroke in adult life: the Helsinki birth cohort study. Stroke 2007;38:264-270.

10. Ohlsson C, Bygdell M, Sondén A, Jern C, Rosengren A, Kindblom JM. BMI increase through puberty and adolescence is associated with risk of adult stroke. Neurology 2017;89:363369.

11. Gjærde LK, Gamborg M, Ängquist L, Truelsen TC, Sørensen TIA, Baker JL. Association of childhood body mass index and change in body mass index with first adult ischemic stroke. JAMA Neurol 2017;74:1312-1318.

12. Baker JL, Olsen LW, Andersen I, Pearson S, Hansen B, Sørensen Tla. Cohort profile: the Copenhagen School Health Records Register. Int J Epidemiol 2009;38:656-662.

13. Andersen TF, Madsen $M$, Jørgensen J, Mellemkjoer $L$, Olsen JH. The Danish National Hospital Register: a valuable source of data for modern health sciences. Dan Med Bull 1999;46:263268.

14. Juel K, Helweg-Larsen K. The Danish registers of causes of death. Dan Med Bull 1999;46:354-357.

15. Cole TJ, Lobstein T. Extended international (IOTF) body mass 
index cut-offs for thinness, overweight and obesity. Pediatr Obes 2012;7:284-294.

16. Rich-Edwards JW, Kleinman K, Michels KB, Stampfer MJ, Manson JE, Rexrode KM, et al. Longitudinal study of birth weight and adult body mass index in predicting risk of coronary heart disease and stroke in women. BMJ 2005;330:1115.

17. Hyppönen E, Leon DA, Kenward MG, Lithell H. Prenatal growth and risk of occlusive and haemorrhagic stroke in Swedish men and women born 1915-29: historical cohort study. BMJ 2001;323:1033-1034.

18. Lawlor DA, Ronalds G, Clark H, Smith GD, Leon DA. Birth weight is inversely associated with incident coronary heart disease and stroke among individuals born in the 1950s: findings from the Aberdeen Children of the 1950s prospective cohort study. Circulation 2005;112:1414-1418.

19. Heshmati A, Chaparro MP, Koupil I. Maternal pelvic size, fetal growth and risk of stroke in adult offspring in a large Swedish cohort. J Dev Orig Health Dis 2016;7:108-113.

20. Martyn CN, Barker DJ, Osmond C. Mothers' pelvic size, fetal growth, and death from stroke and coronary heart disease in men in the UK. Lancet 1996;348:1264-1268.

21. Gamborg M, Byberg $L$, Rasmussen $F$, Andersen PK, Baker JL, Bengtsson $C_{1}$ et al. Birth weight and systolic blood pressure in adolescence and adulthood: meta-regression analysis of sex- and age-specific results from 20 Nordic studies. Am J Epidemiol 2007;166:634-645.

22. Yoon SS, Gu Q, Nwankwo T, Wright JD, Hong Y, Burt V. Trends in blood pressure among adults with hypertension: United States, 2003 to 2012. Hypertension 2015;65:54-61.
23. Kim TJ, Lee JW, Kang HT, Cho MC, Lim HJ, Kim JY, et al. Trends in blood pressure and prevalence of hypertension in Korean adults based on the 1998-2014 KNHANES. Yonsei Med J 2018;59:356-365.

24. Gamborg $M$, Andersen $P K$, Baker JL, Budtz-Jørgensen $E_{1}$ Jørgensen $T$, Jensen $G$, et al. Life course path analysis of birth weight, childhood growth, and adult systolic blood pressure. Am J Epidemiol 2009;169:1167-1178.

25. Baker JL, Olsen LW, Sørensen TI. Childhood body-mass index and the risk of coronary heart disease in adulthood. N Engl J Med 2007;357:2329-2337.

26. Biffi A, Cortellini L, Nearnberg CM, Ayres AM, Schwab K, Gilson $A$, et al. Body mass index and etiology of intracerebral hemorrhage. Stroke 2011;42:2526-2530.

27. Lindekleiv H, Sandvei MS, Njølstad I, Løchen ML, Romundstad $P R$, Vatten $L$, et al. Sex differences in risk factors for aneurysmal subarachnoid hemorrhage: a cohort study. Neurology 2011;76:637-643.

28. Gjærde LK, Truelsen TC, Baker JL. Childhood stature and growth in relation to first ischemic stroke or intracerebral hemorrhage. Stroke 2018;49:579-585.

29. Jensen CB, Gamborg M, Heitmann B, Sørensen TI, Baker JL. Comparison of birth weight between school health records and medical birth records in Denmark: determinants of discrepancies. BMJ Open 2015;5:e008628.

30. Galobardes B, Smith GD, Lynch JW. Systematic review of the influence of childhood socioeconomic circumstances on risk for cardiovascular disease in adulthood. Ann Epidemio/ 2006; 16:91-104 
Supplementary Table 1. Associations of childhood BMI at ages 8, 9, 10, 11, and 12 years with risks of subarachnoid hemorrhage among women and men

\begin{tabular}{|c|c|c|c|c|c|}
\hline \multirow{2}{*}{ Sex } & \multirow{2}{*}{ Age (yr) } & \multirow{2}{*}{ Number } & \multirow{2}{*}{ Cases } & \multicolumn{2}{|c|}{$\mathrm{SAH}, \mathrm{HR}(95 \% \mathrm{Cl})$} \\
\hline & & & & Only BMI & Adjusted for birth weight \\
\hline \multirow[t]{5}{*}{ Women } & 8 & 111,965 & 450 & $0.99(0.90-1.09)$ & $1.02(0.93-1.12)$ \\
\hline & 9 & 107,708 & 453 & $0.97(0.88-1.07)$ & $0.99(0.90-1.09)$ \\
\hline & 10 & 104,642 & 454 & $0.94(0.85-1.03)$ & $0.96(0.87-1.06)$ \\
\hline & 11 & 103,686 & 452 & $0.93(0.85-1.03)$ & $0.95(0.86-1.05)$ \\
\hline & 12 & 102,589 & 454 & $0.94(0.85-1.03)$ & $0.95(0.87-1.05)$ \\
\hline \multirow[t]{5}{*}{ Men } & 8 & 116,872 & 250 & $0.93(0.81-1.06)$ & $0.93(0.81-1.06)$ \\
\hline & 9 & 111,842 & 252 & $0.93(0.81-1.06)$ & $0.93(0.81-1.06)$ \\
\hline & 10 & 108,331 & 250 & $0.92(0.80-1.05)$ & $0.91(0.80-1.05)$ \\
\hline & 11 & 107,287 & 250 & $0.94(0.82-1.07)$ & $0.94(0.82-1.08)$ \\
\hline & 12 & 106,026 & 249 & $0.94(0.82-1.07)$ & $0.94(0.82-1.07)$ \\
\hline
\end{tabular}

HRs and 95\% Cls are given for a 1-unit increase in BMI z-score. All analyses are stratified by birth cohort.

$\mathrm{BMI}$, body mass index; $\mathrm{SAH}$, subarachnoid hemorrhage; $\mathrm{HR}$, hazard ratio; $\mathrm{Cl}$, confidence interval. 
Supplementary Table 2. Risks of ICH or SAH per $500 \mathrm{~g}$ increase in birth weight among women and men diagnosed within the last 10 years of follow-up

\begin{tabular}{lcccccc}
\hline \multirow{2}{*}{ Sex } & \multicolumn{2}{c}{ ICH } & \multicolumn{3}{c}{ SAH } \\
\cline { 2 - 7 } & Number & Cases & HR $(95 \% \mathrm{Cl})$ & Number & Cases & $\mathrm{HR}(95 \% \mathrm{Cl})$ \\
\hline Women & 115,514 & 346 & $0.99(0.93-1.06)$ & 116,859 & 147 & $0.82(0.70-0.96)$ \\
Men & 120,451 & 492 & $0.90(0.85-0.95)$ & 121,831 & 71 & $0.93(0.75-1.45)$ \\
\hline
\end{tabular}

All analyses are stratified by birth cohort.

$\mathrm{ICH}$, intracerebral hemorrhage; $\mathrm{SAH}$, subarachnoid hemorrhage; $\mathrm{HR}$, hazard ratio; $\mathrm{Cl}$, confidence interval. 
Supplementary Table 3. Associations of childhood BMI at age 7 and 13 years with risks of SAH among women and men diagnosed within the last 10 years of follow-up

\begin{tabular}{|c|c|c|c|c|c|}
\hline \multirow{2}{*}{ Sex } & \multirow{2}{*}{ Age (yr) } & \multirow{2}{*}{ Number } & \multirow{2}{*}{ Cases } & \multicolumn{2}{|c|}{$\mathrm{SAH}, \mathrm{HR}(95 \% \mathrm{Cl})$} \\
\hline & & & & Only BMI & Adjusted for birth weight \\
\hline \multirow[t]{2}{*}{ Women } & 7 & 111,717 & 137 & $0.92(0.77-1.10)$ & $0.96(0.81-1.15)$ \\
\hline & 13 & 101,210 & 144 & $0.88(0.74-1.05)$ & $0.90(0.76-1.07)$ \\
\hline \multirow[t]{2}{*}{ Men } & 7 & 116,441 & 69 & $1.10(0.86-1.43)$ & $1.13(0.87-1.49)$ \\
\hline & 13 & 104,236 & 66 & $0.97(0.74-1.26)$ & $0.98(0.74-1.28)$ \\
\hline
\end{tabular}

HRs and 95\% Cls are given for a 1-unit increase in BMI z-score. All analyses are stratified by birth cohort.

$\mathrm{BMI}$, body mass index; $\mathrm{SAH}$, subarachnoid hemorrhage; $\mathrm{HR}$, hazard ratio; $\mathrm{Cl}$, confidence interval. 
Supplementary Table 4. Associations of childhood height at ages 7 to 13 years with risks of SAH among women and men

\begin{tabular}{|c|c|c|c|c|}
\hline Sex & Age (yr) & Number & Cases & $\mathrm{SAH}, \mathrm{HR}(95 \% \mathrm{Cl})$ \\
\hline \multirow[t]{7}{*}{ Women } & 7 & 112,394 & 482 & $0.83(0.76-0.91)$ \\
\hline & 8 & 113,197 & 488 & $0.83(0.76-0.90)$ \\
\hline & 9 & 108,643 & 490 & $0.82(0.75-0.90)$ \\
\hline & 10 & 105,452 & 492 & $0.83(0.76-0.91)$ \\
\hline & 11 & 104,455 & 491 & $0.83(0.76-0.91)$ \\
\hline & 12 & 103,404 & 492 & $0.84(0.77-0.92)$ \\
\hline & 13 & 101,895 & 487 & $0.83(0.76-0.91)$ \\
\hline \multirow[t]{7}{*}{ Men } & 7 & 117,224 & 277 & $0.98(0.87-1.10)$ \\
\hline & 8 & 118,143 & 280 & $0.98(0.87-1.10)$ \\
\hline & 9 & 112,792 & 282 & $0.99(0.88-1.12)$ \\
\hline & 10 & 109,158 & 279 & $1.01(0.90-1.14)$ \\
\hline & 11 & 108,059 & 279 & $1.02(0.90-1.15)$ \\
\hline & 12 & 106,829 & 278 & $1.02(0.91-1.15)$ \\
\hline & 13 & 105,017 & 276 & $1.05(0.93-1.18)$ \\
\hline
\end{tabular}

HRs and 95\% Cls are given for a 1-unit increase in height z-score. All analyses are stratified by birth cohort.

$\mathrm{SAH}$, subarachnoid hemorrhage; $\mathrm{HR}$, hazard ratio; $\mathrm{Cl}$, confidence interval. 

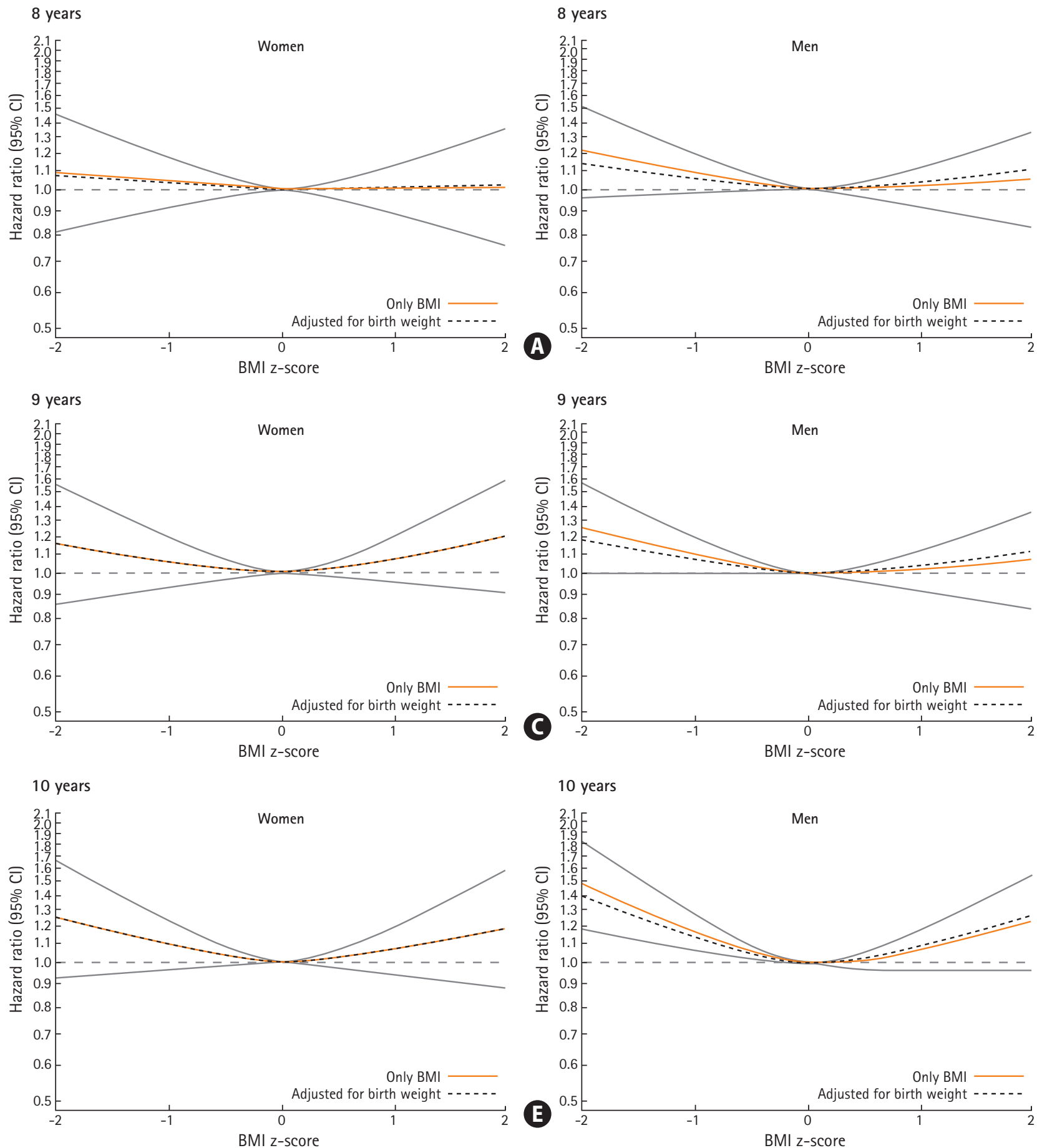

Supplementary Figure 1. Continued. 

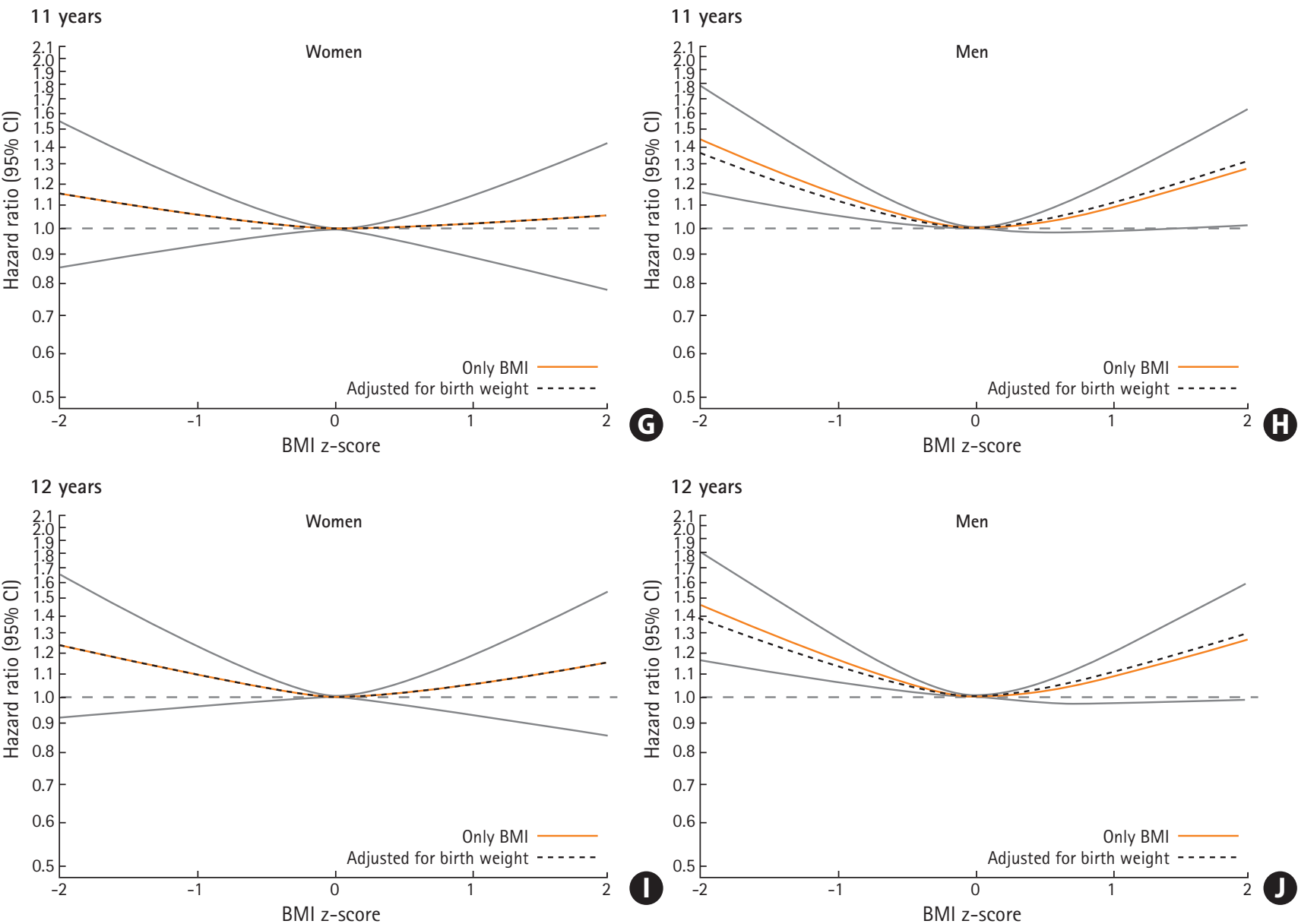

Supplementary Figure 1. Associations of childhood body mass index at age 8, 9, 10, 11, and 12 years with risks of intracerebral hemorrhage among women and men. Hazard ratios and 95\% confidence intervals (Cls) are given for a 1-unit increase in body mass index (BMI) Z-score. All analyses are stratified by birth cohort. (A) Women, 8 years. (B) Men, 8 years. (C) Women, 9 years. (D) Men, 9 years. (E) Women, 10 years. (F) Men, 10 years. (G) Women, 11 years. (H) Men, 11 years. (I) Women, 12 years. (J) Men, 12 years. 

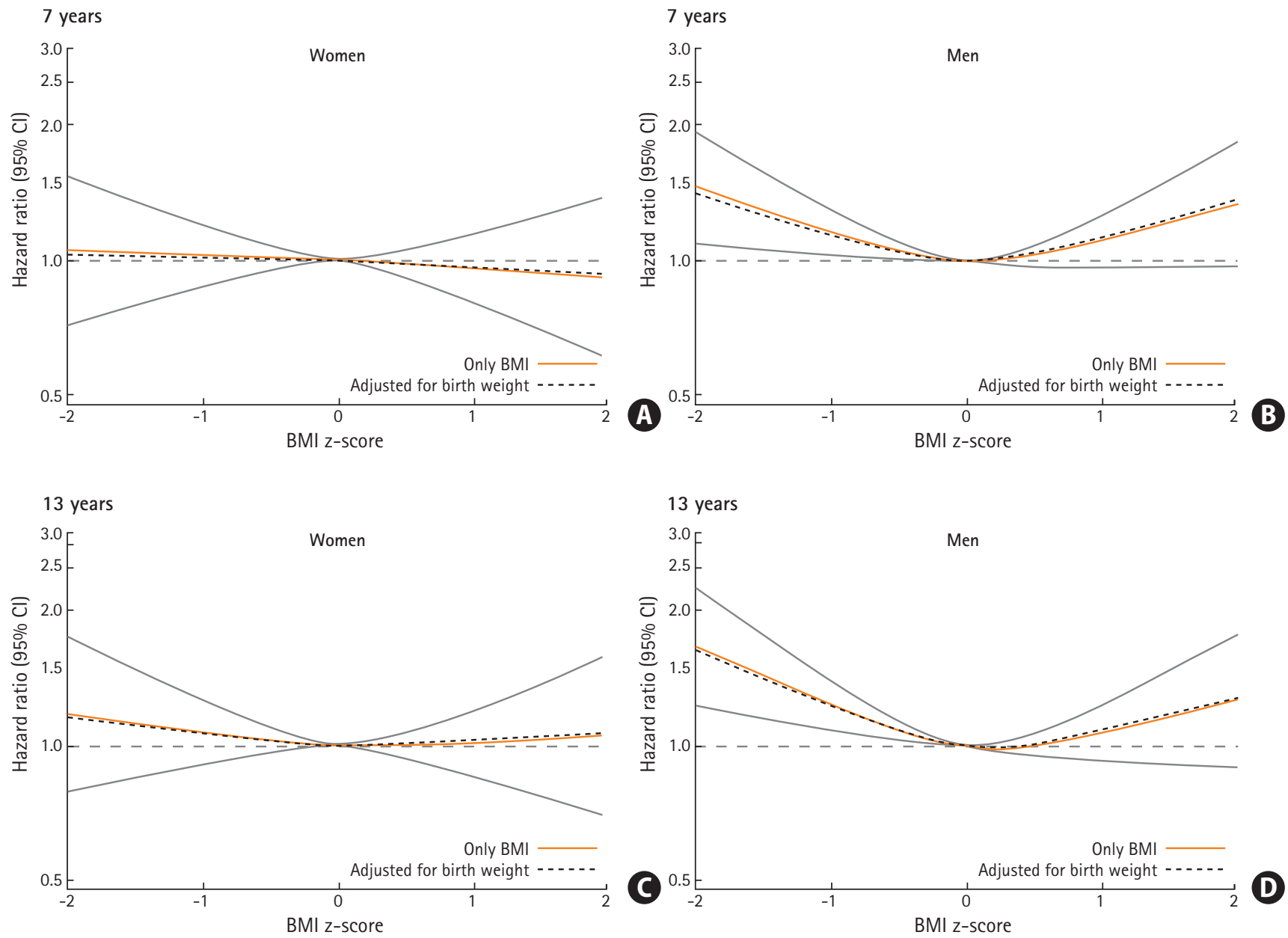

Supplementary Figure 2. Associations of childhood body mass index at age 7 and 13 years with risks of intracerebral hemorrhage among women and men diagnosed within the last 10 years of follow-up. Hazard ratios and 95\% confidence intervals (Cls) are given for a 1-unit increase in body mass index (BMI) zscore. All analyses are stratified by birth cohort. (A) Women, 7 years. (B) Men, 7 years. (A) Women, 13 years. (B) Men, 13 years. 